\title{
Study on fatigue failure characteristics of asphalt mixtures under different test methods
}

\author{
Gui Hou',2 a, Shuangshuang Wang ${ }^{3, b}$ \\ 1School of Highway, Chang'an University, Xi'an, 710064, China \\ 2Traffice Construction Engineering Quality Supervision Bureau in Inner-Mongolia Autonomous \\ Region, Hohhot, 010020, China \\ 3School of Traffic and Transportation Engineering, Changsha University of Science and \\ Technology, Changsha, 410114, China \\ a: 184369402@qq.com, b: 1574360876@qq.com
}

\begin{abstract}
Keywords: road engineering; asphalt mixture; accelerated loading test; stiffness decay regularity; damage mechanics
\end{abstract}

Abstract: In order to truthfully reveal the stiffness decay of asphalt mixture, the nonlinear fatigue damage evolution model of asphalt mixture based on accelerated loading test are established accordingly mixture, first, the accelerated loading test is conducted on the formed standard asphalt mixture specimens by accelerated loading test system, and the moduli of resilience of the asphalt mixture under different loading times are tested by materials testing system, Based on the basic theory of damage mechanics, the decay of modulus is defined as the damage variable, and the stiffness decay equation and the nonlinear fatigue damage evolution model. The results of the nonlinear fatigue damage evolution model takes into account the loading history, which more faithfully reflects the fatigue damage of asphalt mixtures under cyclic loading; the stiffness decay regularity under the condition of accelerated loading test is different from that of the common fatigue loading methods in the third stage during fatigue failure process, the decay rate increases at first and then decreases.

\section{Introduction}

Transportation is the lifeblood of the national economy, with the development of economic construction, road traffic conditions and natural environment has become increasingly grim, traffic flow in the daily increase in Express, highway overload, overloading phenomenon is widespread, new roads in the opening soon after the different forms of destruction, seriously affecting the use of road performance. The fatigue crack is one of the main forms of pavement fatigue failure ${ }^{[1-2]}$, which adds a lot of capital to the maintenance and repair of pavement, therefore, it is very important to reveal the fatigue performance of asphalt pavement under real load environment. ${ }^{[3-4]}$.

In order to reveal the mechanism of fatigue damage of asphalt mixture and the law of damage development, the design method of asphalt pavement is improved theoretically and the reliability of the correction factor is improved to ensure the satisfactory performance of asphalt pavement. Both domestic and foreign, road researchers pay sufficient attention to the fatigue properties of asphalt mixtures and carry out a large number of indoor and outdoor experimental studies. The SHRP research plan compares the experimental results obtained under different experimental methods, That four-point bending fatigue test in the evaluation of the fatigue properties of asphalt mixture is superior to other test methods, and as a standard test fatigue properties, provides a standard test method, the method has become AASHTO standard test method ${ }^{[5]}$. Van Dijk and Bonnuare and other researchers 
will be the material stiffness modulus down to the initial state of $1 / 2$ as the termination condition of the test, then the number of loading cycles of the test specimen is the fatigue life of the specimen ${ }^{[6-7]}$. Yeo I et al. ${ }^{[8]}$ established the cumulative loss model of asphalt mixture of full-scale test and analyzed the correlation between the results of full-scale test and the results of laboratory tests. Kozel M et al ${ }^{[9]}$ considered the APT tester the best choice for evaluating new pavement structures and materials. However, due to the high cost of full-scale test, some small-scale units do not possess sufficient economic conditions to carry out relevant research. In contrast, the small-sample test has less investment and short time and thus has more applications. However, in the fatigue test, the stress state of the test specimen is relatively different from that of the pavement in actual operation. Therefore, a more realistic and economical method is needed to reveal the law of fatigue damage development of the asphalt mixture.

Joint research on the fatigue properties of asphalt and bituminous mixtures was organized by RILEM TC101-BAT and TC152-PBM Lions Clubs and was completed in 1996. The conclusion of the research shows that the classic fatigue analysis shows that the fatigue performance deterioration of asphalt pavement structure and materials is limited. It is understood that in order to recognize the fatigue damage phenomenon of asphalt mixture and to establish the mathematical model of its complex fatigue damage process, further research ${ }^{[10]}$. Although the theories about the fatigue behavior of asphalt mixtures have matured at home and abroad, the existing models for standardizing different traffic loads are too simple and the Miner linearity is always taken into account when considering the repeated effects of traffic loads The theory and method of fatigue damage ${ }^{[11-12]}$ did not consider the influence of traffic load history and nonlinear accumulation on the pavement structure failure. It is considered that the accumulation of damage is linear, that is to say, the loading order is changed arbitrarily, which has no effect on the current damage value does not meet the actual road conditions fatigue damage. An example of this gets a better illustration of the problem. A heavy truck with a rear axle weight of $150 \mathrm{kN}$ is driven 100 times on a newly constructed road surface, one hundred times on a heavily damaged road surface at the end of use, it is obvious that damage and destruction are not the same.

Based on this, this paper first, the accelerated loading test is conducted on the formed standard asphalt mixture specimens by accelerated loading test system, and the moduli of resilience of the asphalt mixture under different loading times are tested by materials testing system, Based on the basic theory of damage mechanics, the decay of modulus is defined as the damage variable, and the stiffness decay equation and the nonlinear fatigue damage evolution model. 


\section{Fatigue Damage Model and the Derivation of the Stiffness Decay Model}

Definition of damage variables

According to the original definition of damage defining the fatigue damage factor of the material

$$
D=1-\frac{A}{A_{0}}
$$

According to the theory of damage mechanics and strain equivalence, the constitutive relation after injury can still be expressed as:

$$
\varepsilon_{N}=\frac{\sigma}{E_{N}(1-D)}=\frac{\sigma}{E_{0}}
$$

The damage variables defined by the modulus of the elastic modulus of the material can be expressed as:

$$
D=1-\frac{E}{E_{0}}
$$

Nonlinear fatigue damage model

The main characteristic of nonlinear fatigue damage model is damage associated with loading history, namely under the same conditions (such as stress amplitude, mean stress, temperature, frequency, etc.), the load at different stages of their damage effects are different.

A common nonlinear fatigue damage evolution model is proposed ${ }^{[13-15]}$

$$
\frac{d D}{d N}=\left[1-(1-D)^{1+\gamma}\right]^{\alpha}\left[\frac{\sigma}{M(1-D)}\right]^{\gamma}
$$

Integrate formula (4):

$$
D(N)=1-\left[1-\left(N(1+\gamma)(1-\alpha)\left(\frac{\sigma}{M}\right)^{\gamma}\right)^{\frac{1}{1-\alpha}}\right]^{\frac{1}{1+\gamma}}
$$

When $N=N_{f} D(N)=1$, the equation of fatigue life can be derived from the formula(5)

$$
N_{f}=\frac{1}{(1+\gamma)(1-\alpha)}\left(\frac{\sigma}{M}\right)^{-\gamma}
$$

The equation of damage can be derived when generate formula six to formula five:

$$
D(N)=1-\left[1-\left(\frac{N}{N_{f}}\right)^{\frac{1}{1-\alpha}}\right]^{\frac{1}{1+\gamma}}
$$

Where: $\sigma$ is Stress amplitude, M, $\alpha$ and $\gamma$ are material parameters which are temperature-dependent make $k=\frac{M^{\gamma}}{(1+\gamma)(1-\alpha)}, n=\gamma$, formula six changed to: 


$$
N_{f}=k\left(\frac{1}{\sigma}\right)^{n}
$$

formula seven changed to:

$$
D(N)=1-\left[1-\left(\frac{N}{k\left(\frac{1}{\sigma}\right)^{n}}\right)^{\frac{1}{1-\alpha}}\right]^{\frac{1}{1+\gamma}}
$$

Combining formula three and formula nine

$$
\frac{E}{E_{0}}=\left[1-\left(\frac{N}{k\left(\frac{1}{\sigma}\right)^{n}}\right)^{\frac{1}{1-\alpha}}\right]^{\frac{1}{1+\gamma}}
$$

Where: $E$ Is the stiffness of the specimen corresponding to acceleration $\mathrm{N}$ times; ${ }^{E_{0}}$ is the initial stiffness of the specimen; $\sigma$ is the loading times; $N$ is the stress amplitude; $k, n$ is the parameter related to the fatigue life of the mixture and is the temperature-dependent material parameter.

Equation (10) is the nonlinear stiffness decay model of asphalt mixture.

\section{Materials and Test}

\section{Materials}

The performance indexes of SBS modified asphalt are shown in Tab.1, the physical and chemical properties of aggregates are shown in Tab.2 and the dense skeleton type gradation of aggregate were chosen according to "Specifications for Design of Highway Asphalt Pavement" [16], the detail information is presented in Fig.2. The optimum asphalt ratio was determined by Marshall Tests, the test results are displayed in Tab.3.

Table.1 Performance Index of SBS (I-D) modified asphalt

\begin{tabular}{llc}
\hline Technical indexes & Result & Specification \\
\hline penetration $25^{\circ} \mathrm{C}, 100 \mathrm{~g}, 5 \mathrm{~s}(0.1 \mathrm{~mm})$ & 55.92 & $30 \sim 60$ \\
ductility $5 \mathrm{~cm} / \mathrm{min}, 5^{\circ} \mathrm{C}(\mathrm{cm})$ & 34.32 & $\geq 20$ \\
softening point $\mathrm{TR} \& \mathrm{~B}\left({ }^{\circ} \mathrm{C}\right)$ & 79.35 & $\geq 60$ \\
\hline
\end{tabular}

Table. 2 physical and chemical properties of aggregates

\begin{tabular}{lllll}
\hline Items & $\begin{array}{l}\text { Crushing } \\
\text { value }\end{array}$ & $\begin{array}{l}\text { Content of needle-like } \\
\text { particles }\end{array}$ & $\begin{array}{l}\text { Content of } \\
\mathrm{SiO}_{2}\end{array}$ & $\begin{array}{l}\text { Apparent } \\
\text { density }\end{array}$ \\
\hline Value & 10.5 & 7.7 & 1.75 & 2.576 \\
Specification & $\leq 26$ & $\leq 20$ & $/$ & $/$ \\
\hline
\end{tabular}

The dense skeleton type gradation of aggregate was shown as Figure 4. 


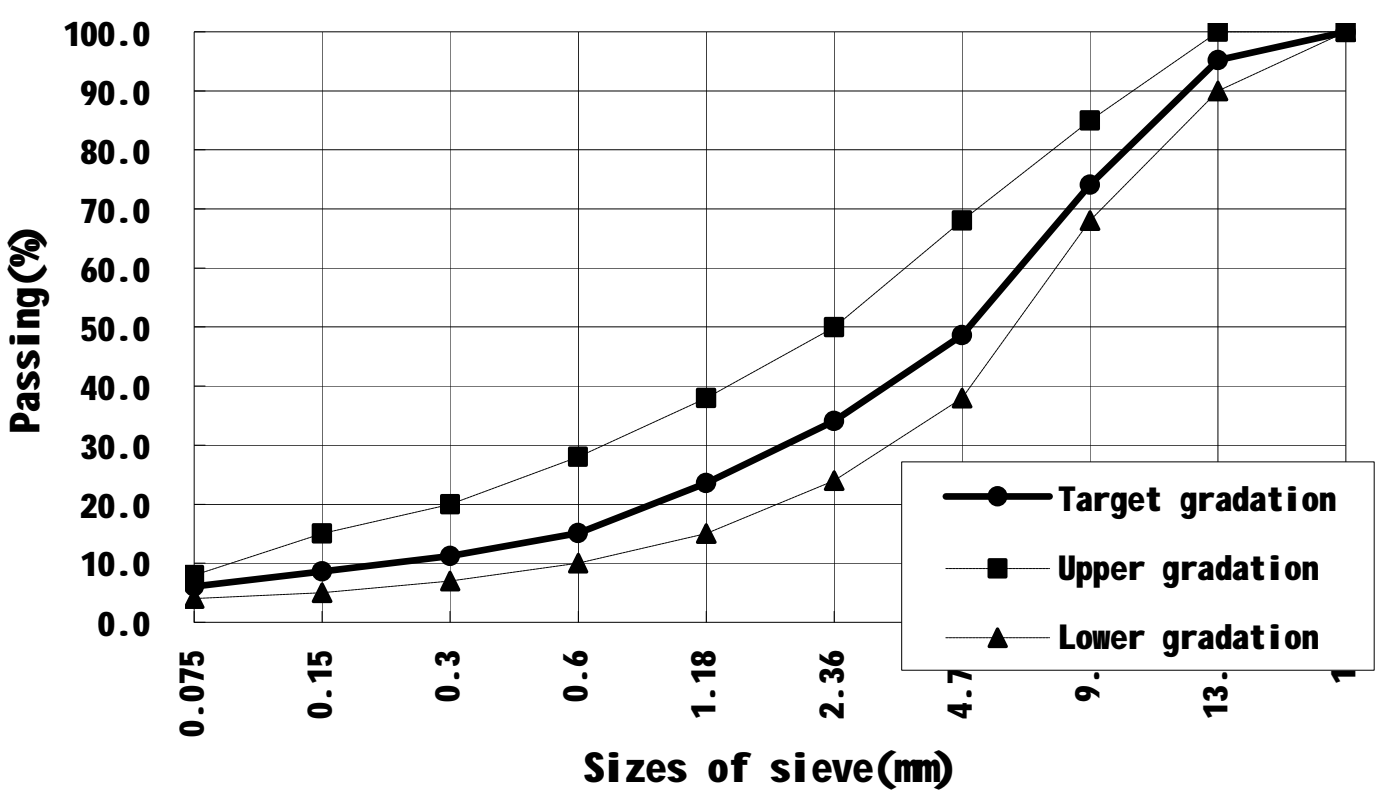

Figure 1 Gradation of Aggregate

Table.3 Marshall Test results at optimal asphalt content

\begin{tabular}{ccccccc}
\hline $\begin{array}{c}\text { Asphalt } \\
\text { aggregate ratio } \\
(\%)\end{array}$ & $\begin{array}{c}\text { Bulk specific } \\
\text { gravity }\left(\mathrm{g} \cdot \mathrm{cm}^{-3}\right)\end{array}$ & $\begin{array}{c}\text { Volume of } \\
\text { air voids VV }\end{array}$ & $\begin{array}{c}\text { Voids filled } \\
\text { with asphalt }\end{array}$ & $\begin{array}{c}\text { Voids in } \\
\text { mineral }\end{array}$ & $\begin{array}{c}\text { Marshall } \\
\text { stability }\end{array}$ & $\begin{array}{c}\text { Flow } \\
\text { value }\end{array}$ \\
& & & VFA $(\%)$ & $\begin{array}{c}\text { aggregate } \\
\text { VMA/\% }\end{array}$ & $(\mathrm{kN})$ & $(0.1 \mathrm{~mm})$ \\
\hline $5.2 \%$ & 2.54 & 4.51 & 67.20 & 16.11 & 12.71 & 27.89 \\
\hline
\end{tabular}

Type and size of specimen

This test using the Marshall experimental $\Phi 150 \times 100$ cylindrical specimen, and then cut into accelerated loading test required for the standard specimen, as shown in Fig.3:

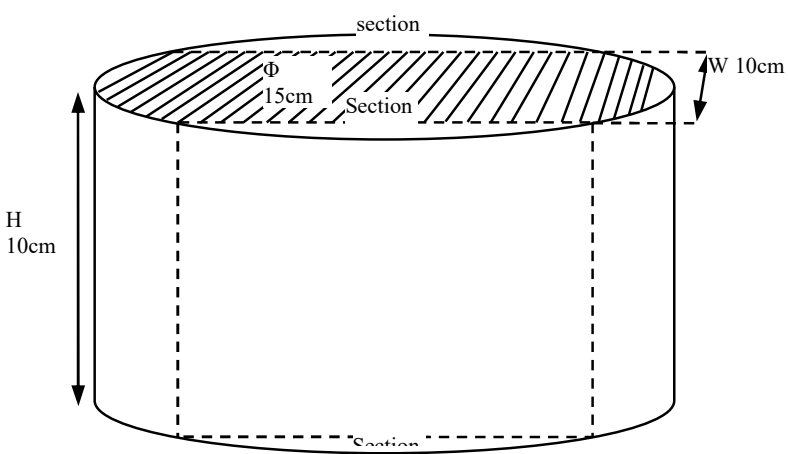

(a)

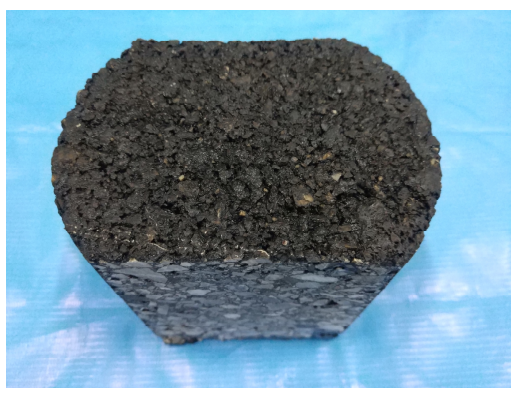

(b)

Fig.2 Shape and size of standard specimen 
Test equipment introduction

This experiment uses the accelerated loading test system MMLS1/3(Model Mobile Load Simulator at 1/3rd scale) (As shown in Fig.1) imported by South Africa and the material test system MTS (Material Test System) (As shown in Fig.2) imported by the United States

Accelerated loading system (MMLS1/3) through the test shaft controllable load and temperature of continuous loading on the pavement material or structure, loading frequency can be increased to 7200 times/h, the maximum load can reach $2.9 \mathrm{KN}$, acting on the pneumatic tire with the diameter of $300 \mathrm{~mm}, 850 \mathrm{KPa}$ value can reach the maximum wheel pressure, can simulate the actual pavement is the different vehicle speed and vehicle load, as shown in Fig.1 (a). Fig.1 (b) for the test grooves, both sides have 12 screws, used to fix the specimen, both ends of the two steel clamping, so as to ensure that the nine specimens form a close whole.

Multi-functional material test system is the most advanced multi-function test system in the world, which can be used for static tensile, pressure, bending, shearing, high frequency and low frequency fatigue test of civil engineering materials and composite materials, and the hydraulic loading method can provide fast and stable load. The supporting environment chamber can provide a variety of static and dynamic temperature environment, and can be coupled with the load and temperature, comprehensive consideration of various conditions under the force of specimens

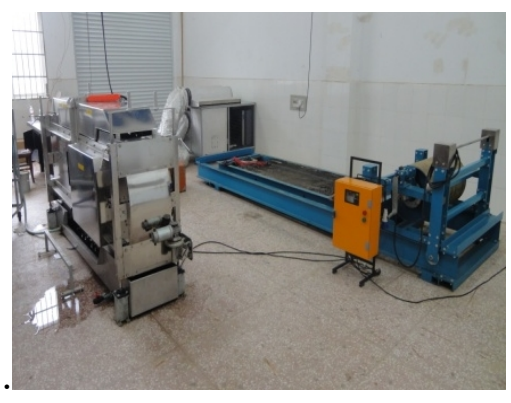

(a)MMLS1/3 Acceleration loading system

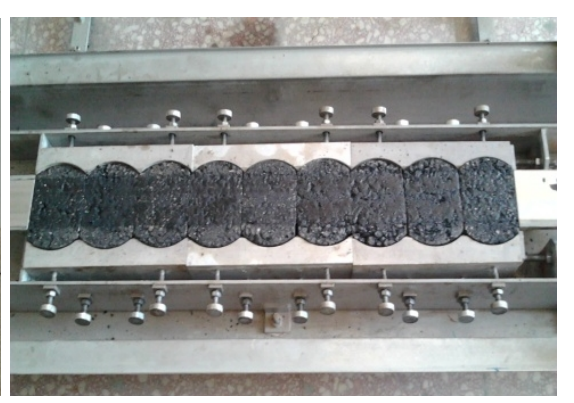

(b) MMLS1/3 Test grooves

Fig.3 Accelerated loading test equipment

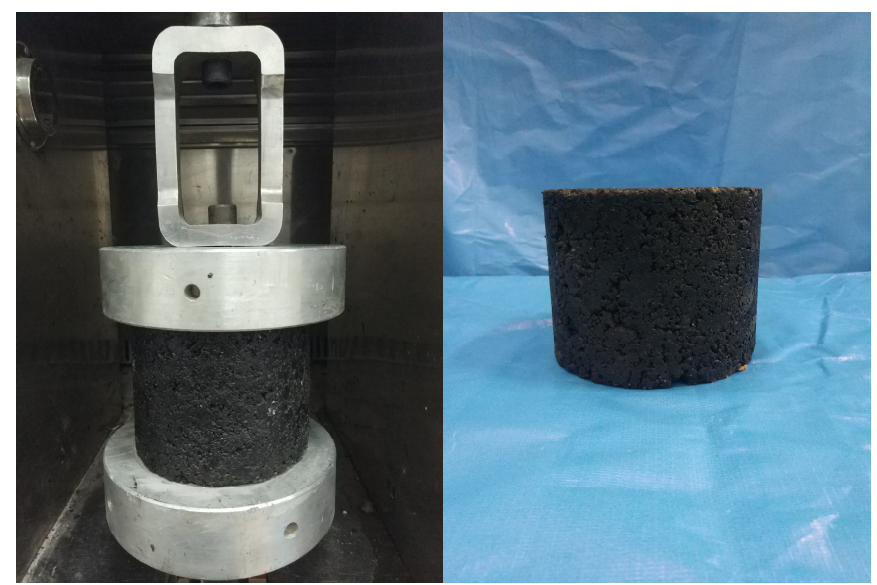

Fig.4 The diagram of strength and fatigue test equipment 


\section{Experiment scheme}

The wheel pressure is $0.7 \mathrm{MPa}$, the loading speed is 5200 times $/ \mathrm{h}$, and the temperature is at $20{ }^{\circ} \mathrm{C}$. The loading frequency, loading wheel pressure and ambient temperature remain unchanged during the test.

Through the accelerated loading of 10,30,50,70,100,120, 140 thousand times, 1.6 million times of different loading times of the shaped test piece, the test piece after each level loading is placed in the MTS environmental chamber in $20^{\circ} \mathrm{C}$ environment conservation more than 2 hours, and then use the MTS material test system to measure the compressive resilience modulus. The resilient modulus test according to 6 levels of loading, respectively $0.25,0.50,0.75,1,1.25,1.50 \mathrm{~mm}, 6$ as grade displacement test load, loading rate of $2 \mathrm{~mm} / \mathrm{min}$, each loaded into a class, and at the same rate of unloading and loading, static pressure $30 \mathrm{~s}$. Unloading test of the next level in loading, as shown in Fig.5:

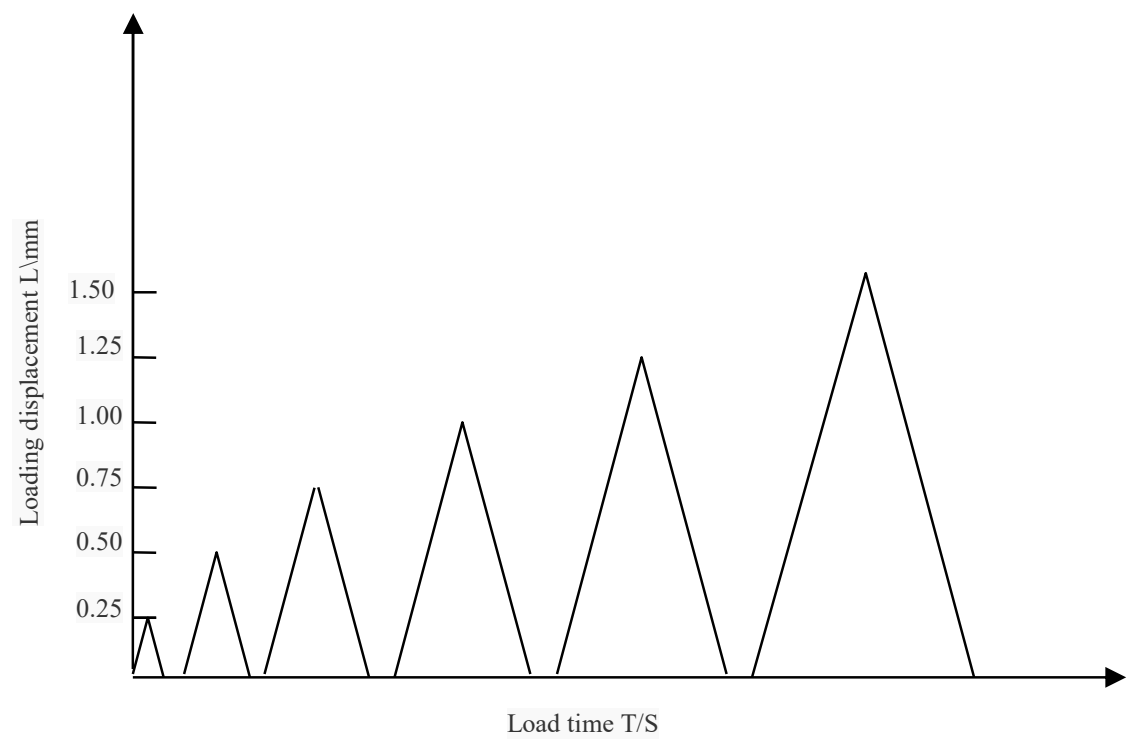

Fig.5 Loading and unloading process curve for modulus of resilience test

According to "asphalt and asphalt mixture test regulations of Highway Engineering" [17], the modulus of resilience modulus under different loading times is calculated. The average modulus of modulus of resilience of SBS-AC13 asphalt mixture under different loading times is shown in Tab.2.

Tab.4 Stiffness testing data of asphalt mixture

\begin{tabular}{|c|c|c|c|c|c|c|c|c|c|}
\hline $\begin{array}{l}\text { Loads / } \\
\text { million } \\
\text { times }\end{array}$ & 0 & 10 & 30 & 50 & 70 & 100 & 120 & 140 & 160 \\
\hline $\begin{array}{l}\text { Stiffness } \\
\text { average } \\
/ \mathrm{MPa}\end{array}$ & $\begin{array}{l}1881 . \\
51\end{array}$ & $\begin{array}{l}1826 . \\
02\end{array}$ & $\begin{array}{l}1695 \\
65\end{array}$ & $\begin{array}{l}1661 . \\
15\end{array}$ & $\begin{array}{l}1588 . \\
59\end{array}$ & $\begin{array}{l}1590 . \\
25\end{array}$ & $\begin{array}{l}1518 . \\
69\end{array}$ & $\begin{array}{l}1303 . \\
48\end{array}$ & $\begin{array}{l}1232 . \\
59\end{array}$ \\
\hline
\end{tabular}




\section{Test Results Analysis}

Stiffness decay equation

The stiffness expression (10) derived from the theory is used to fit the elastic modulus data of asphalt mixture under different loading times. The fitting curve is shown in Figure 6:

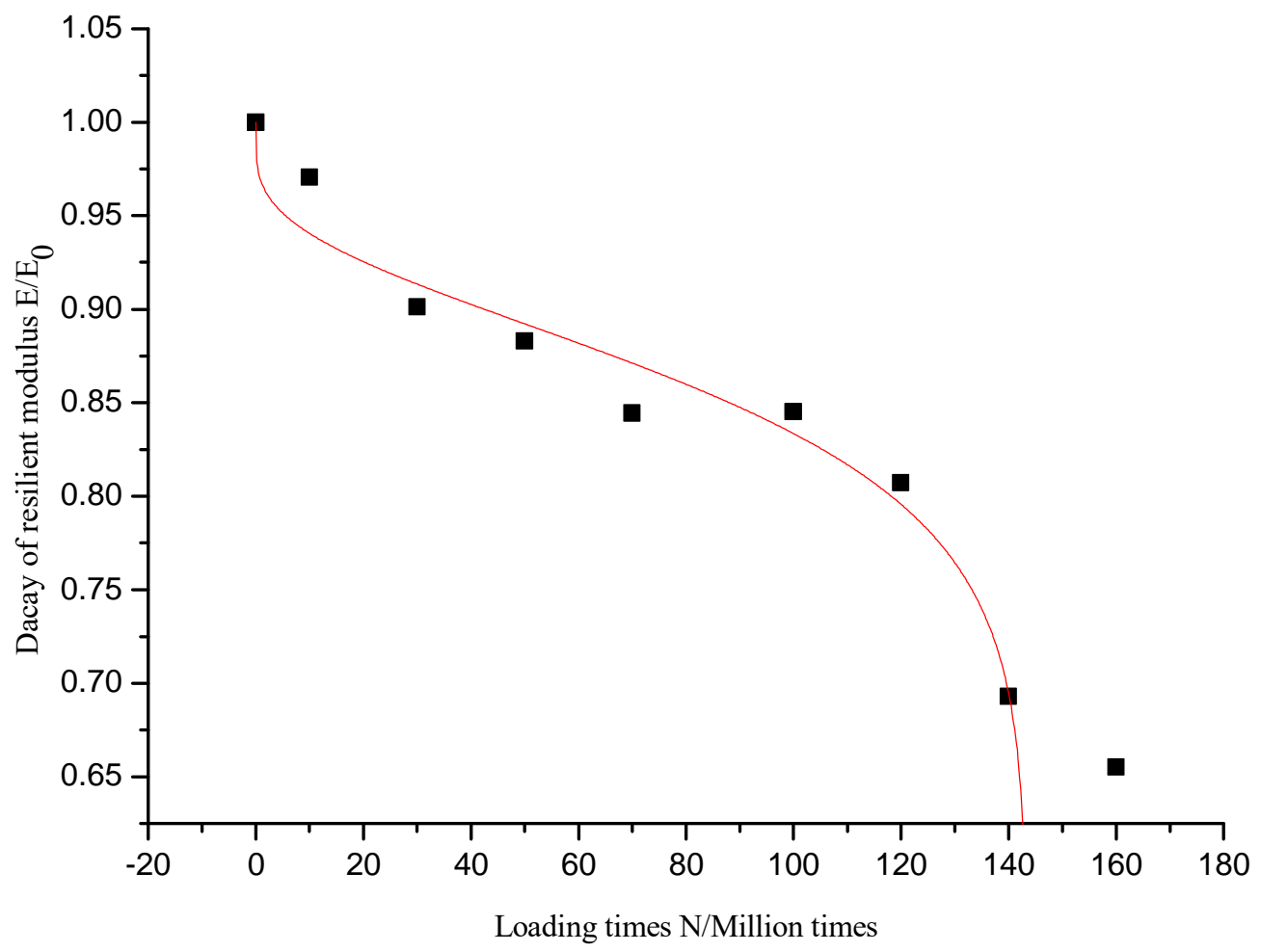

Fig.6 Decay regularity of resilient modulus of asphalt mixture

The fitted stiffness equation parameters are shown in Table 4:

Tab.5 Parameters of stiffness decay equation of asphalt mixture

\begin{tabular}{llllll}
\hline $\begin{array}{l}\text { Parameter } \\
\text { symbol }\end{array}$ & $\mathrm{k}$ & $\mathrm{n}$ & $\alpha$ & $\gamma$ & $R^{2}$ \\
\hline $\begin{array}{l}\text { Parameter } \\
\text { fitting value }\end{array}$ & 36.837 & 3.813 & -4.149 & 13.793 & 0.966 \\
\hline
\end{tabular}

From the parameter values fit in Table 3 , it can be seen that there is a good correlation between the regression curves of the elastic moduli of the asphalt mixture obtained by using the formula (10) and the loading times, and the correlation coefficient is above 0.96. In the equation, $\mathrm{k}$ and $\mathrm{n}$ are parameters related to fatigue life. The results of fatigue test of commonly used asphalt mixtures in domestic and overseas high-grade roads are listed in ${ }^{[18]}$, and the value of $\mathrm{n}$ varies between 2.56 and $5.72^{[18]}$. In this paper, the value of n obtained during curve fitting is between 2.56 and 5.72, which is consistent with the related research results. This shows that the formula (10) E-N fit is reasonable.

From (8) and Table 3, the corresponding parameter values can be estimated asphalt mixture fatigue life: 


$$
N_{f}=k\left(\frac{1}{\sigma}\right)^{n}=36.837 \times\left(\frac{1}{0.7}\right)^{3.813}=143.305
$$

As can be seen from Eq. (11), the fatigue life of asphalt mixture is about 1.43 million times. When it reaches 1.6 million times, it exceeds the fatigue life of asphalt mixture, so the fitted curve does not extend to 1.6 million times.

The law of stiffness decay

As can be seen from Figure 5, as the loading times increase, the stiffness of asphalt mixture decays in three stages. In the first stage, before loading to 200,000 times, the stiffness of asphalt mixture decayed quickly and the initial stiffness decay rate was larger. With the increase of loading times, the decay rate decreased gradually. This is mainly due to the original small defects in the specimen stress concentration under fatigue stress, the local first to produce plastic deformation, micro-cracks can be rapidly expanded, the ability of materials to reduce external forces, a sharp decrease in stiffness. In the second stage, before loading to 1200000 times, the stiffness of asphalt mixture was roughly linearly attenuated and the attenuation rate remained stable. This is mainly because, with the increase of the fatigue load, the high-density energy accumulated in the local area near the internal defect is transferred and released through the plastic deformation and the expansion of defects, and the energy balance of the entire system is automatically realized, thereby restraining the interior of the structure The further development of the damage, re-achieve a new relatively stable state, under a cyclic load damage evolution occurs at a steady rate. In the third stage, the stiffness of asphalt mixture drastically decayed, the decay rate gradually increased, and the material produced fatigue failure. At this stage, the structure has been subjected to cyclic stress for a long time. Due to the gradual accumulation of material damage, the mechanical properties of the material decrease continuously. When the structural resistance is close to the external load, the internal damage of the structure aggravates until the fatigue breaks down. The three-stage variation of stiffness decay of asphalt mixture based on accelerated loading tests is similar to the fatigue test results of other indoor loading methods ${ }^{[19]}$.

In order to eliminate the discrepancy of the test data caused by the experimental error and to further understand the stiffness decay characteristics of the asphalt mixture in the accelerated loading process, the stiffness decay equation obtained in Table 3 was used to calculate the stiffness of the asphalt mixture under different loading times Rebound modulus value is corrected. From (11) shows that the fatigue life of SBS-AC13 asphalt mixture is 143.305 million times, the stiffness of asphalt mixture is corrected to 1.4 million times. The correction results are shown in Table 5: 
Tab6 Asphalt mixture stiffness corrected by fitting equation (unit: $\mathrm{MPa}$ )

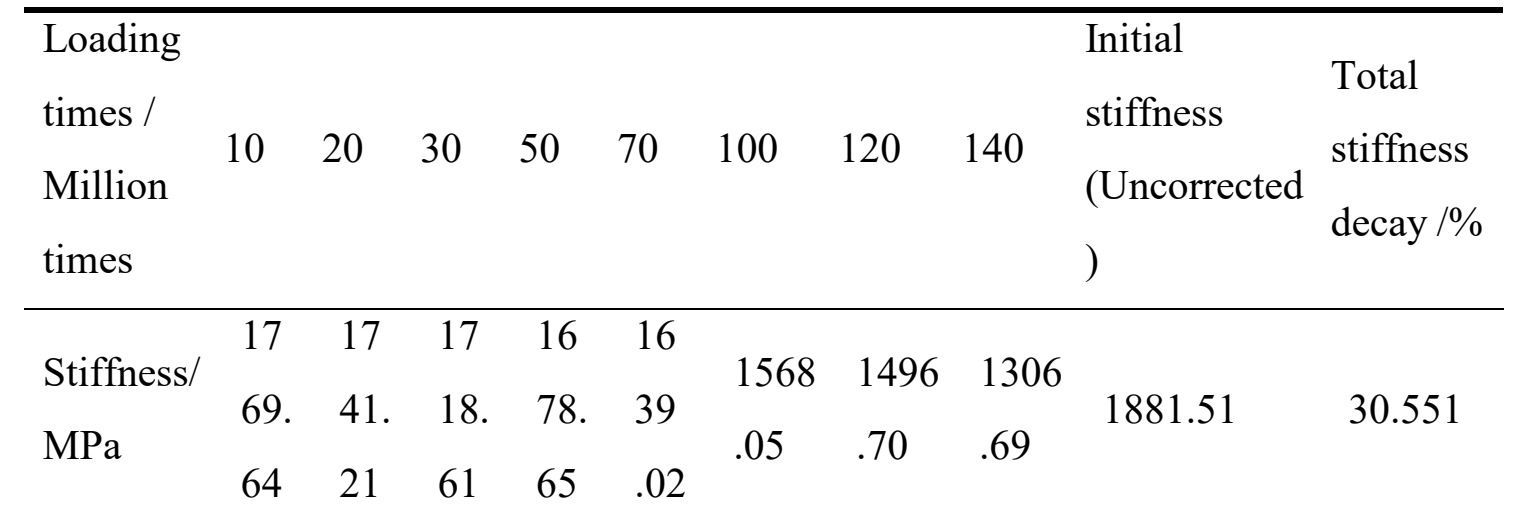

From Table 4, it can be seen that the stiffness attenuation is $7.457 \%$ when loaded to 200,000 times, and the stiffness attenuation is $30.551 \%$ when loaded to 1.4 million times. The stiffness attenuation due to the first 200,000 cycles of loading accounts for the total attenuation $24.407 \%$, but the number of loadings only accounted for $14.286 \%$ of the total number of loadings. Therefore, it is found that the cyclic loadings at the initial stage of loading are more damaging to the structure. This is mainly due to micro-cracks in the asphalt mixture specimens during forming and rolling. These original micro-defects will cause local stress concentration under fatigue stress, which will promote the expansion of cracks and aggravate the internal Damage rate, the mechanical properties of the material will be rapidly reduced. Therefore, asphalt pavement construction, strict control of construction quality, improve pavement uniformity, reduce the porosity of the construction, to improve the durability of the pavement will have a significant role.

According to Table 5, calculate the stiffness attenuation rate of different loading sections, the calculation results are shown in Table 6:

Table 7 different sections of the loading section stiffness decay rate (unit: $\mathrm{MPa} /$ million times)

\begin{tabular}{|c|c|c|c|c|c|c|c|c|c|}
\hline $\begin{array}{l}\text { Load } \\
\text { interval } \\
\text { section / } \\
\text { million } \\
\text { times }\end{array}$ & $\begin{array}{l}0-10 \\
(\text { Mill } \\
\text { ion } \\
\text { times })\end{array}$ & $\begin{array}{l}\text { 10-20 } \\
\text { (Mill } \\
\text { ion } \\
\text { times) }\end{array}$ & $\begin{array}{l}\text { 20-30 } \\
\text { (Mill } \\
\text { ion } \\
\text { times) }\end{array}$ & $\begin{array}{l}30-50 \\
(\text { Mill } \\
\text { ion } \\
\text { times) }\end{array}$ & $\begin{array}{l}50-70 \\
(\text { Mill } \\
\text { ion } \\
\text { times) }\end{array}$ & $\begin{array}{l}\text { 70-100 } \\
\text { (Mill } \\
\text { ion } \\
\text { times) }\end{array}$ & $\begin{array}{l}100-12 \\
0 \\
(\text { Mill } \\
\text { ion } \\
\text { times) }\end{array}$ & $\begin{array}{l}120-14 \\
0 \\
\text { (Mill } \\
\text { ion } \\
\text { times) }\end{array}$ & $\begin{array}{l}140-16 \\
0 \\
\text { (Mill } \\
\text { ion } \\
\text { times) }\end{array}$ \\
\hline $\begin{array}{l}\text { Stiffness } \\
\text { decay rate }\end{array}$ & & & & & & & & & \\
\hline $\begin{array}{l}\text { / } \\
(\mathrm{MPa} \cdot \\
\text { million } \\
\text { times - 1) }\end{array}$ & $\begin{array}{l}11.18 \\
7\end{array}$ & 2.842 & 2.260 & 1.998 & 1.981 & 2.366 & 3.567 & 9.501 & 3.705 \\
\hline
\end{tabular}


From the data in Table 6, we can get the change law of the stiffness decay rate of asphalt mixture with loading times, as shown in Fig. 7:

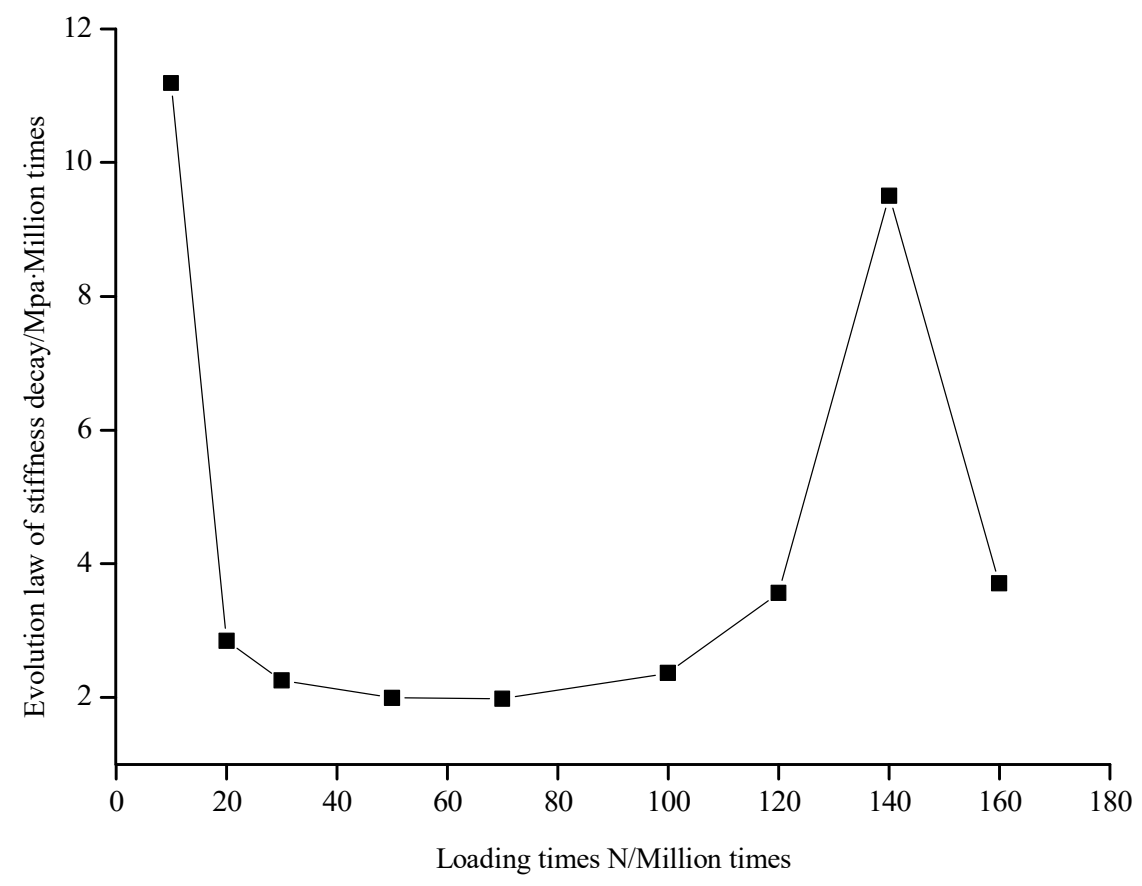

Fig.7 Evolution law of stiffness decay rate with the loading times

As can be seen from Figure 7, the stiffness decay rate of the mixture is very high at the initial stage of loading, ie, 200,000 times. With the increase of the loading times, the decay rate decreases rapidly. When the loading times are from 200,000 times After 120 times of loading, the stiffness attenuation rate is relatively stable, and is in a stable stage of structural damage development. After 1.2 million loads, the stiffness attenuation rate gradually increases. When the loading rate reaches about 1.4 million times, the stiffness attenuation rate reaches the maximum value, As loading continues, the rate of stiffness decay begins to decrease again.

The evolution process of the stiffness decay rate based on the accelerated loading test is in good agreement with the fatigue test results of the other two loading modes under the stress control mode. The third stage is different. The latter in the third stage of the fatigue process, the specimen stiffness decay rate continues to increase until the final fracture of the specimen. However, in the third stage, the stiffness decay rate of the specimen firstly increases rapidly and reaches the maximum value when the load reaches a certain number of times. At the same time, the stiffness decay rate begins to decrease again when it is loaded continuously, which is similar to the common fatigue test The law of stiffness decay is different. This is mainly due to the fatigue test under other loading modes in the stress control mode and the unimpeded periphery of the specimen, and the cracks in the structure during the fatigue failure stage are developed smoothly, and the stiffness of the material drops sharply. However, during the accelerated loading test, due to the constraint of the periphery of the specimen (as shown in Figure 1), the fatigue damage stage will not be able to continue until the internal cracks 
in the structure expand to a certain extent. The damage rate inside the structure will also be limited. Therefore, the stiffness of the specimen decay rate first increased and then decreased. Even if loading continues, the test specimen will not completely crack, and the further expansion of the crack will be limited by the surrounding restraint. Finally, local cracks will be formed and fall off, resulting in fatigue failure, as shown in Figure 8:
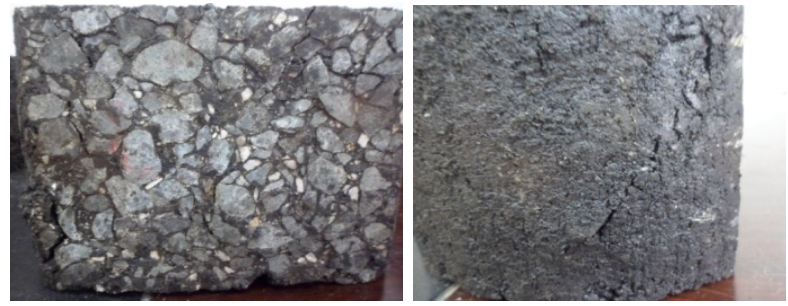

Fig.8 Fatigue damage form of asphalt mixture specimen under $14 \times 105$ loading times

\section{Conclusions}

This paper starts from the basic theory of damage mechanics, The decay of the defined modulus is the damage variable, The stiffness decay equation is derived from the theoretical derivation $\frac{E}{E_{0}}=\left[1-\left(\frac{N}{k\left(\frac{1}{\sigma}\right)^{n}}\right)^{\frac{1}{1-\alpha}}\right]^{\frac{1}{1+\gamma}}$ 。Using this equation to fit the rebound modulus of asphalt mixture under different loading times, it is found that it has a good correlation, and it is reasonable to prove that the model of stiffness decay is established.

Based on accelerated loading test of asphalt mixture stiffness decay process are the three stages of change, and the load of the fatigue test indoor and other similar results, but the third stage stiffness attenuation rate evolution process are different. Accelerated loading test, in the fatigue damage stage, stiffness attenuation speed first increased and then decreased, due to the perimeter of the specimen constraint function the specimen is not completely craze, eventually to local fracture penetration caused by cement fall off. In the fatigue failure stage, the stiffness attenuation rate increases until the final fracture of the specimen.

Due to the lack of research on the stiffness decay characteristics of the asphalt mixture based on the accelerated loading test, the results of the study are not compared. In addition, the test samples are small and the conclusions are limited. So this article research results should be a lot of perfect follow-up testing and validation, in order to establish a scientific and reasonable asphalt mixture stiffness decay model, is able to build up a real simulation of the actual loading ways of the pavement 
fatigue life of asphalt mixture under the condition of forecast model and a nonlinear fatigue damage evolution model to provide the reference.

\section{Acknowledgements}

This work was financially supported by the National Natural Science Foundation of China(51578081, 51608058).

\section{References}

[1] Zheng Jiang-long. New Structure Design of Durable Asphalt Pavement Based on Life Increment[J]. China Journal of Highway \& Transport, 2014, 27(1):1-7.

[2] Wang $\mathrm{C}$, Zhang $\mathrm{H}$, Castorena $\mathrm{C}$, et al. Identifying fatigue failure in asphalt binder time sweep tests[J]. Construction \& Building Materials, 2016, 121:535-546.

[3] Zgútová K, Šrámek J, Kuricová S, et al. Rheology, Deformational Properties and Fatigue of the Surface Asphalt Mixtures [J]. Procedia Engineering, 2016, 153:909-914.

[4] Xuedong G, Mingzhi S, Wenting D, et al. Research on the fatigue whole life of asphalt mixture based on the nonlinear damage theory[J]. Construction \& Building Materials, 2017, 156:546-554.

[5] Liu G, Jia Y, Yang T, et al. Fatigue performance evaluation of asphalt mixtures based on energy-controlled loading mode[J]. Construction \& Building Materials, 2017, 157:348 —356.

[6] AASHTO Standard Specifications for Transportation Materials and Method of Sampling and Testing(23nd edition, Part 2B)[S].America:AASHTO Publishing,2003:154-63.

[7] Ning Li,A.A.A. Molenaar,A.C. Pronk.Effect of Specimen Size on Fatigue Behavior of Asphalt Mixture in Laboratory Fatigue Tests.7th RILEM International Conference on Cracking in Pavements.2012,4:827-836.

[8] Masoud K. Darabi, Rashid K. Abu Al-Rub, Eyad A. Masad.Constitutive modeling of fatigue damage response of asphalt concrete materials with consideration of micro-damage healing.International Journal of Solids and Structures, 2013,50:2901-2913.

[9] Yeo I, Suh Y, Mun S, et al. Development of a remaining fatigue life model for asphalt black base through accelerated pavement testing $[\mathrm{J}]$. Construction \& Building Materials, 2008, 22(8):1881-1886.

[10]Kozel M, Kyselica M, Mikolaj J, et al. Accelerated Pavement Testing in Slovakia $\mathfrak{\imath}[\mathrm{J}]$. Procedia Engineering, 2016, 153:310-316.

[11] Castro M, Sánchez J A. Estimation of asphalt concrete fatigue curves - A damage theory approach[J]. Construction \& Building Materials, 2008, 22(6):1232-1238.

[12] Liu Hong-fu. Research on Nonlinear Fatigue Damage Properties of Asphalt Mixture Based on the Decay of Strength and Stiffness[D]. Changsha University of Science and Technology,2012.

[13]Zheng Jiang-long, LV Song-tao. Nonlinear Fatigue Damage Model for Asphalt Mixtures[J]. China Journal of Highway \& Transport, 2009, 22(5):21-28.

[14]LV Song-tao. Axle load conversion of asphalt pavement based on nonlinear fatigue damage[J]. Engineering Mechanics, 2012.

[15]LV Song-tao. Fatigue Performance of Aged Asphalt Mixture Characterized By Real Stress Ratio[J]. Journal of Highway \& Transportation Research \& Development, 2012, 29(10):1-6. 
[16]JTG D50-2017, Specifications for Design of Highway Asphalt Pavement[S],2017.

[17]JTG E20-2011, Specifications and Test Methods of Bitumen and Bituminous Mixtures for Highway Engineering [S], (2011).

[18]LV Song-tao. Research on Viscoelastic Fatigue Damage of Aged Asphalt Mixture[D]. Changsha: Changsha University of Science and Technology,2008.

[19] Qian Guo-ping,LIU Hong-fu,Zheng Jian-long,et al. The Tension and Compression Fatigue Damage Test of Asphalt Mixture[J]. Journal of Highway and Transportation Research and Development,2012,29(3):1-6. 